\title{
Physicochemical Properties of Sb, Sn, Zn, and Sb-Sn System
}

\author{
Tomasz Gancarz • Władysław Gasior • \\ Hani Henein
}

Received: 5 September 2011 / Accepted: 19 January 2013 / Published online: 10 February 2013 (C) The Author(s) 2013. This article is published with open access at Springerlink.com

\begin{abstract}
The physicochemical properties, viscosity, density, and surface tension, were measured using the discharge crucible method (DC) on five alloys of Sb-Sn. The performance of the DC method was demonstrated with measurements on pure metals $\mathrm{Sb}, \mathrm{Sn}, \mathrm{Zn}$, and comparisons with the corresponding literature data. The results reported in this study are for $\mathrm{Sb}-\mathrm{Sn}$ alloys containing $(10,20,25,50$, and 75) at $\%$ of Sb at $550 \mathrm{~K}$ to $850 \mathrm{~K}$. The results show that all the physicochemical properties decrease with decreasing temperature and increase with increasing Sb content in the alloy. The experimentally measured surface-tension values are compared with the Butler model. Several models for viscosity are compared and discussed.
\end{abstract}

Keywords Density $\cdot$ Discharge crucible $\cdot \mathrm{Sb} \cdot \mathrm{Sb}-\mathrm{Sn}$ alloys $\cdot \mathrm{Sn} \cdot \mathrm{Surface}$ tension Viscosity $\cdot \mathrm{Zn}$

\section{Introduction}

$\mathrm{Sb}-\mathrm{Sn}$ alloys belong to a group of materials being considered for application in the electronics industry. In recent years some publications have confirmed that this system is a good candidate for use as a high-temperature solder material [1,2]. Presently, $\mathrm{Ag}, \mathrm{Au}, \mathrm{Cu}, \mathrm{Zn}, \mathrm{Bi}$, and In are used in the electronics industry for high-temperature applications $[3,4]$ such as step soldering technology [5]. However, in order to fully

T. Gancarz $(\varangle) \cdot$ W. Gąsior

Institute of Metallurgy and Materials Science,

Polish Academy of Science, Kraków, Poland

e-mail: nmgancar@imim-pan.krakow.pl

H. Henein

Department of Chemical and Materials Engineering,

University of Alberta, Edmonton, AB, Canada 
develop and apply many of these alloys, greater knowledge on their physicochemical properties and soldering characteristics is needed. Presently, the main interest of numerous research teams has so far been focused on the measurement of many technological properties of these alloys, neglecting the measurements of physicochemical properties such as viscosity.

Looking for a replacement for the PbSn eutectic, Sato and Munakata [6] explored the viscosity of $\mathrm{Sn}-\mathrm{Zn}$ alloys. Since $\mathrm{Zn}$ alloys have poor corrosion resistance, investigators have been considering $\mathrm{Sb}-\mathrm{Sn}$ alloys as possible lead-free solder materials. For pure $\mathrm{Sb}, \mathrm{Sn}$, and $\mathrm{Zn}$ the physicochemical properties, density [7-17], surface tension [18-30], and viscosity [31-46], have been reported in the literature. For the values reported for density, the dilatometric and pycnometric techniques are used for measurements. The sessile-drop and maximum bubble-pressure methods are used for measuring the surface tension, and the oscillation and capillary methods for viscosity. Despite so much data for the pure metals, there is little data for alloys of Sb-Sn $[1,2,20,47,48]$. Values of viscosity for the $\mathrm{Sb}-\mathrm{Sn}$ alloys are difficult to find in the scientific literature. Only the work of Sato and Munakata [47] and Plevachuk et al. [48] reported viscosity measurements for $\mathrm{Sb}-\mathrm{Sn}$ alloys. In the present investigation the viscosity, density, and surface tension of Sb-Sn alloys ((10, 20, 25, 50, and 75) at\% of Sb) have been measured by the discharge crucible method (DC) [49] over the temperature range from $550 \mathrm{~K}$ to $1050 \mathrm{~K}$.

\section{Experimental}

The DC method [49-52] was used in this work to measure the physicochemical properties of Sb-Sn alloys. The method has been described in detail elsewhere and will only be briefly described here. It involves the free outflow of molten metal through an orifice of specified diameter in the bottom of a crucible. From a measurement of the mass of molten metal flowing out of the crucible as a function of time, one can calculate the surface tension, density, and viscosity simultaneously from one experiment. The apparatus for the DC method was constructed and placed in a glove box filled with high purity argon gas, to provide the best possible protective atmosphere during the experiment. The levels of $\mathrm{O}_{2}$ and $\mathrm{H}_{2} \mathrm{O}$ were below $1 \mathrm{ppm}$ as measured by solid-state analyzers for oxygen and moisture. The results presented in this study were performed in the temperature range from $520 \mathrm{~K}$ to $1073 \mathrm{~K}$, and the mass of measured metal used in each test was around $1 \mathrm{~kg}$ to $1.5 \mathrm{~kg}$. The liquid metal temperature was controlled with a thermocouple placed inside the crucible and connected to a temperature controller (Eurotherm working with an uncertainty of $0.1^{\circ} \mathrm{C}$ ), and the difference in melt temperature during a run was less than $1^{\circ} \mathrm{C}$. In order to calibrate the apparatus, measurements of the density, surface tension, and viscosity of pure antimony, tin, and zinc were carried out. Dimensions of the crucible were the same as reported in an earlier study [49] that addressed the properties of $\mathrm{Sn}$ and $\mathrm{Sn}-\mathrm{Ag}$ alloys. The exiting stream of the melt in the crucible needs to fulfill the relation of the Froude number (Fr) to the Bond number (Bo) described by Roach and Henein [50,51]. In this study $F r$ varied from 0.4 to 0.2 for $\mathrm{Sn}$ and $\mathrm{Sb}$, and for $\mathrm{Zn}$ from 0.63 to 0.45 . The values of $\mathrm{Fr}$ was experimentally verified and confirmed. 
The DC method, described in previous studies [49-51], was modified by additional density measurements using a dilatometric method presented in [53]. Using this method, the height of liquid in the crucible was determined using a screw micrometer which gives the height of the volume of liquid metal in the crucible during the course of the experiment. This results in an increased speed of convergence and a more accurate determination of the three properties of the liquid metal tested. Before proceeding with testing of $\mathrm{Sn}-\mathrm{Sb}$ binary alloys, the properties of the three pure metals, $\mathrm{Sb}, \mathrm{Sn}$, and $\mathrm{Zn}$, having purities of $99.99 \%$ were first determined. The experiments were also conducted in the glove box under an atmosphere of pure argon. The gas purity was the same, as in the experiments with the binary alloy. The experiments were performed usually two or three times for each temperature. The resulting calculated fluid properties were always within $1.5 \%$. The main source of error in these experiments was the dilatometric measurements of the density (height of liquid metal). To calculate the parameters of surface tension and viscosity, the numerical scheme used was based on the Hooke-Jeeves method [54].

\section{Results}

\subsection{Physicochemical Properties of Pure Sb, Sn, Zn}

The results obtained using the DC method are compared with those obtained using other experimental techniques. For density determination dilatometric, sessile-drop (SD), and pycnometric methods were used. For surface tension determination the methods of maximum bubble pressure (MBP) and sessile drop (SD) were used. For viscosity determination the capillary method $(\mathrm{CM})$, oscillation crucible measurements $(\mathrm{OM})$, and the rotating-cylinder method (RCM) were used.

The results obtained for the density of antimony are shown in Fig. 1. At temperatures up to $980 \mathrm{~K}$, we have very good agreement with the data reported by Steinberg [13] and Sato and Munakata [47]. The slope of the lines is the same and values are different by about $10 \mathrm{~kg} \cdot \mathrm{m}^{-3}$ at the same temperature with those resulting from the equation proposed by Steinberg for the density of $\mathrm{Sb}$ which is based on literature data from [16,55-58]. However, the results of Fisher and Philips [7] and Greenway [8] for the density are higher over the entire range of temperatures.

In Fig. 2, the results of the surface tension of $\mathrm{Sb}$ agree well with those proposed by Keene [18], by Gasior et al. [20], and by Lauermann and Sauerwald [24]. Surfacetension values from this study are also compared to the data reported by Somol and Beranek [23]. The same trend in the data is observed, and our values are lower by $\sim 4$ $\left(\mathrm{mN} \cdot \mathrm{m}^{-1}\right)$ over the entire range of temperature (within about $\left.1 \%\right)$.

The results of viscosity for pure $\mathrm{Sb}$ are shown in Fig. 3 and compared with literature values. We observe very good agreement with data obtained using oscillation crucible measurement techniques [36], the capillary method [31], and calculations [37].

Figure 4 shows the density of tin, also measured by the DC method and calculated using the numerical scheme based on the method of Hooke-Jeeves. The results obtained from different experimental methods are in good agreement with each other. In Fig. 5, the surface tension of pure $\mathrm{Sn}$ is compared with literature values. We can see 


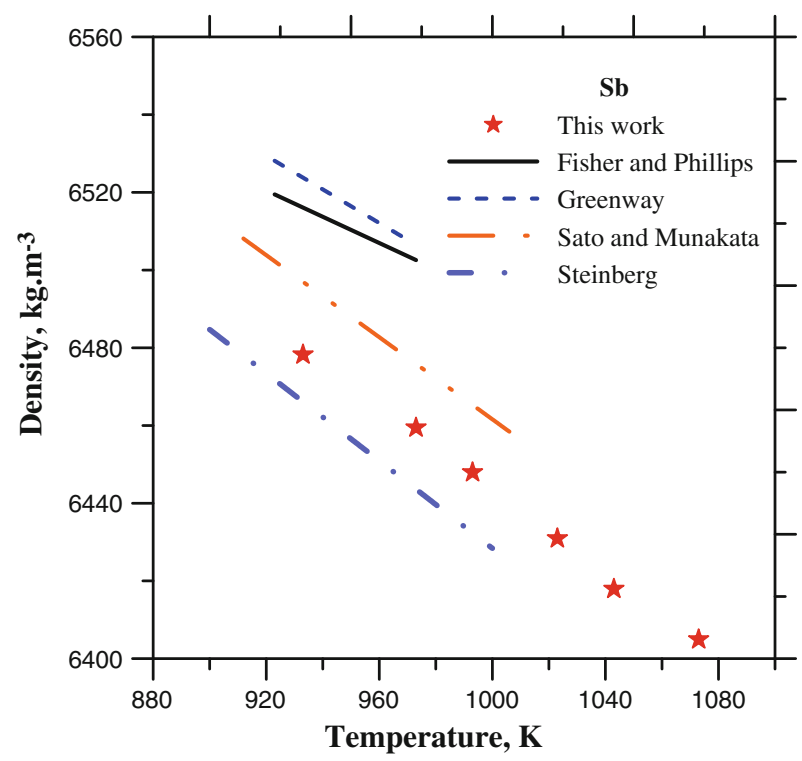

Fig. 1 Density of antimony as a function of temperature compared with literature data of Fisher and Phillips [7], Greenway [8], Sato and Munakata [47], and Steinberg [13]

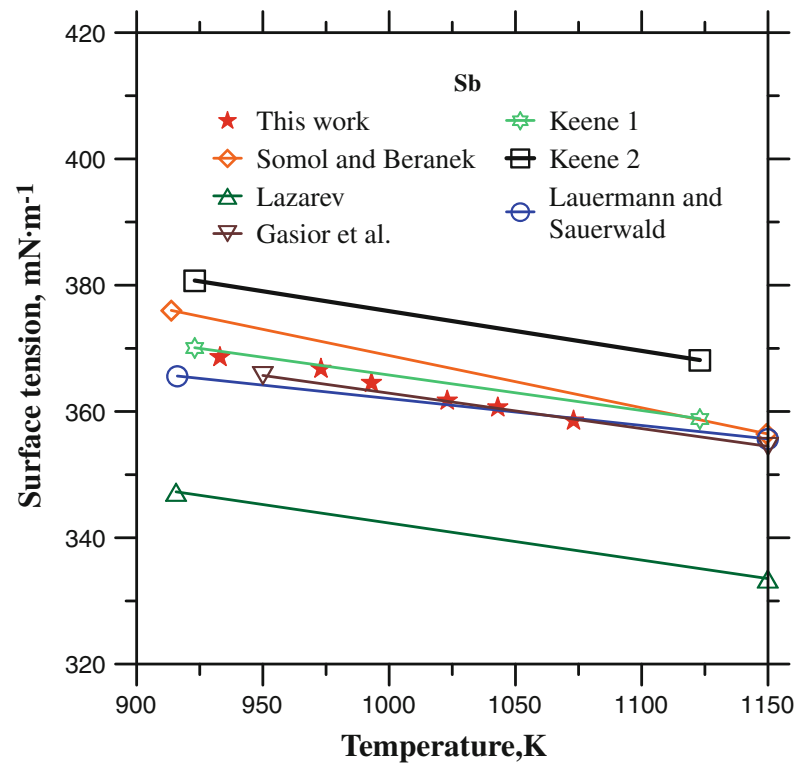

Fig. 2 Surface tension of antimony as a function of temperature compared with literature data of Keene [18] (Keene 1-the average equation from literature data, Keene 2-the proposed equation), Gasior et al. [20], Somol and Beranek [23], Lauermann and Sauerwald [24], and Lazarev [25]

very good agreement between the data obtained in this study, and those obtained using the same DC method reported by Gancarz et al. [49]. Also, very good agreement is 


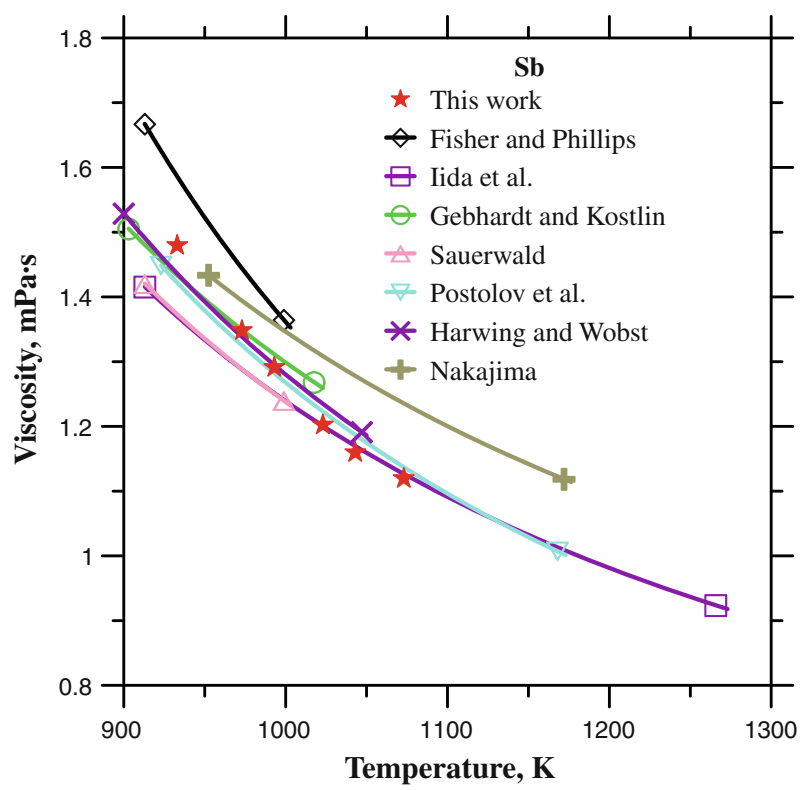

Fig. 3 Viscosity of antimony as a function of temperature compared with literature data of Fisher and Phillips [7]. Sauerwald [29], Iida et al. [31], Gebhardt and Kostlin [34], Postolov et al. [36], Harwing and Wobst [37], and Nakajima [38]

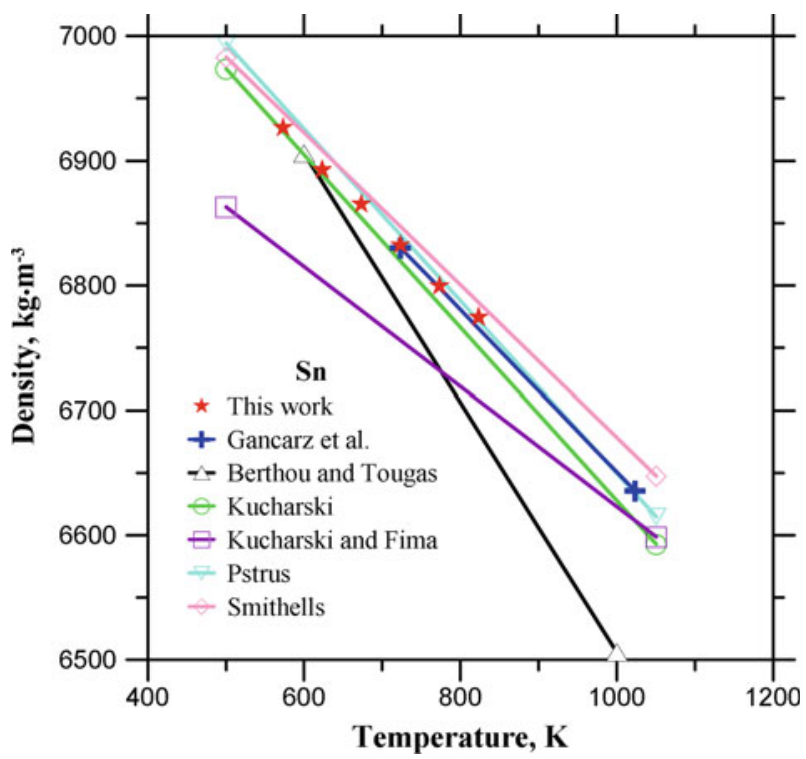

Fig. 4 Density of tin as a function of temperature compared with literature data of Gancarz et al. [49], Smithells [9], Pstrus [10], Kucharski and Fima [14], Kucharski [15], and Berthou and Tougas [16]

seen with data reported by Keene [18], Mills and Su [19], Gasior et al. [20], and Lide [21]. In Fig. 6, we observed excellent agreement between measurements carried out in this study, when compared to those reported in the literature by Gasior et al. [46] and 


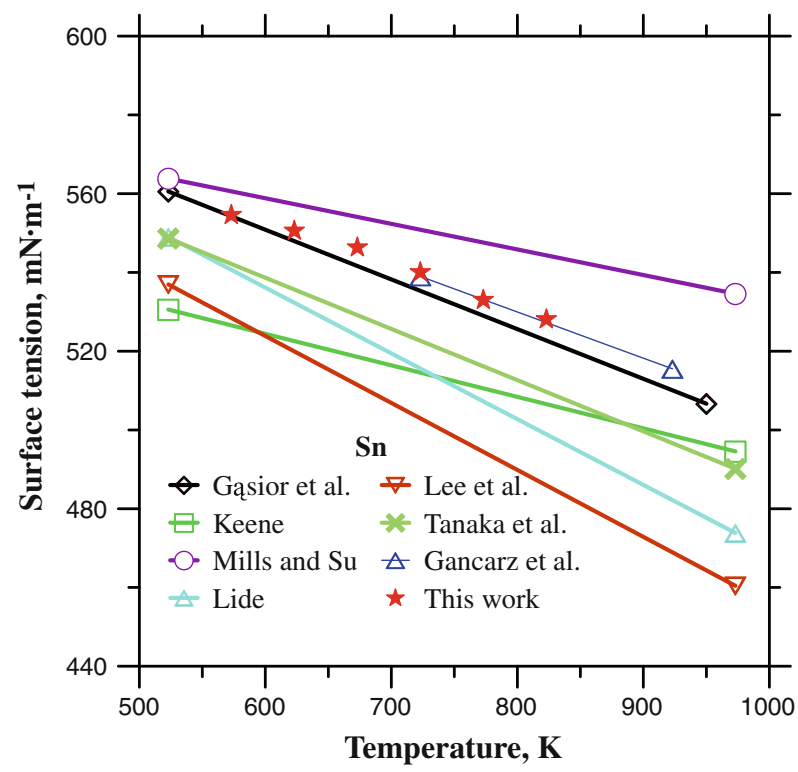

Fig. 5 Surface tension of tin as a function of temperature compared with literature data of Gancarz et al. [49], Keene [18], Mills and Su [19], Gasior et al. [20], Lide [21], Lee et al. [26], and Tanaka et al. [27]

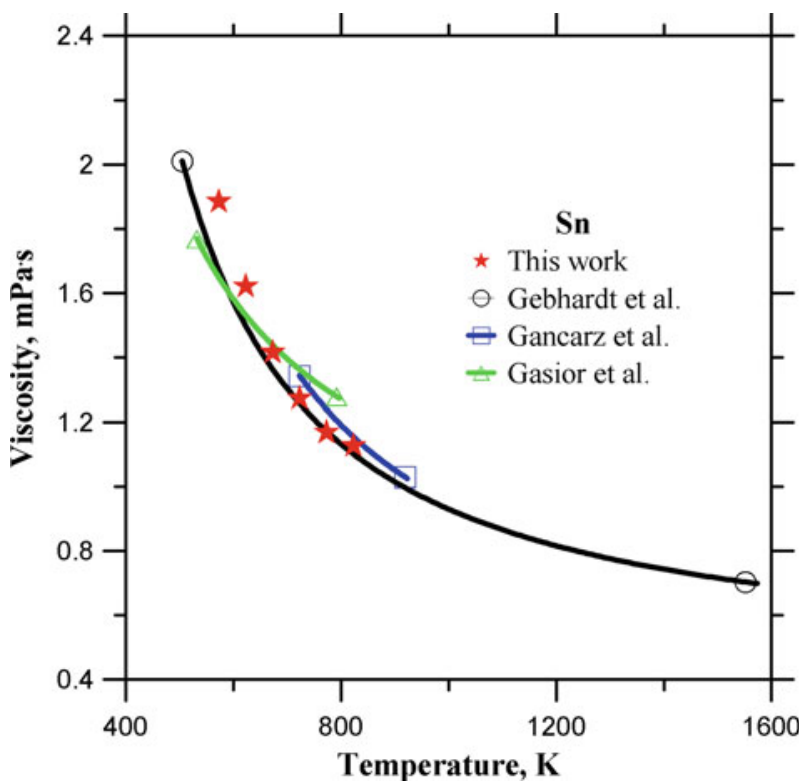

Fig. 6 Viscosity of tin as a function of temperature compared with literature data of Gancarz et al. [49], Gebhardt et al. [32], and Gasior et al. [46]

by Gebhardt and Kostlin [34]. The values of density, surface tension, and viscosity are presented in Tables 1, 2, and 3, respectively. 
Table 1 Parameters of the straight line $A+B T$, with errors $\left(\mathrm{kg} \cdot \mathrm{m}^{-3}\right)$. Density for $\mathrm{Sb}, \mathrm{Sn}$, $\mathrm{Zn}$, and $\mathrm{Sb}-\mathrm{Sn}$ alloys
Table 2 Parameters of the straight line $A+B T$, with errors $\left(\mathrm{mN} \cdot \mathrm{m}^{-1}\right)$. Surface tension for $\mathrm{Sb}, \mathrm{Sn}, \mathrm{Zn}$, and $\mathrm{Sb}-\mathrm{Sn}$ alloys

\begin{tabular}{lllll}
\hline Materials & \multicolumn{4}{l}{$\rho=A+B T\left(\mathrm{~kg} \cdot \mathrm{m}^{-3}\right)$} \\
\cline { 2 - 5 } & $A$ & $\delta A$ & $B$ & $\delta B$ \\
\hline Sn & 7276.6 & 35.0 & -0.613 & 0.044 \\
SnSb10 & 7184.7 & 8 & -0.555 & 0.012 \\
SnSb20 & 7140.3 & 21.1 & -0.534 & 0.033 \\
SnSb25 & 7113.2 & 13.3 & -0.52 & 0.018 \\
SnSb50 & 7055.5 & 11.3 & -0.517 & 0.014 \\
SnSb75 & 7037.8 & 11.3 & -0.561 & 0.025 \\
Sb & 6981.8 & 14.4 & -0.538 & 0.014 \\
Zn & 7156.5 & 16.8 & -0.45 & 0.034 \\
\hline
\end{tabular}

\begin{tabular}{lllll}
\hline Materials & \multicolumn{4}{l}{$\sigma=A+B T\left(\mathrm{mN} \cdot \mathrm{m}^{-1}\right)$} \\
\cline { 2 - 5 } & $A$ & $\delta A$ & $B$ & $\delta B$ \\
\hline $\mathrm{Sn}$ & 617.2 & 2.7 & -0.108 & 0.004 \\
$\mathrm{SnSb10}$ & 598.0 & 1.9 & -0.130 & 0.003 \\
$\mathrm{SnSb} 20$ & 555.6 & 4.5 & -0.117 & 0.007 \\
$\mathrm{SnSb} 25$ & 515.7 & 4.8 & -0.080 & 0.007 \\
$\mathrm{SnSb50}$ & 495.6 & 3.4 & -0.089 & 0.004 \\
$\mathrm{SnSb75}$ & 476.5 & 3.4 & -0.095 & 0.003 \\
$\mathrm{Sb}$ & 439.5 & 4.3 & -0.075 & 0.004 \\
$\mathrm{Zn}$ & 1018.1 & 4.9 & -0.285 & 0.007 \\
\hline
\end{tabular}

Figures 7, 8, 9 present results of the properties measured for $\mathrm{Zn}$ and comparisons with values reported in the literature. In Fig. 7, the results for the density of zinc are compared with literature values $[12,17]$. In all respects very good agreement is observed. The data of Pstrus et al. [11] look very similar, but are slightly shifted to lower values by $10 \mathrm{~kg} \cdot \mathrm{m}^{-3}$. In Fig. 8, the surface tension of $\mathrm{Zn}$ is compared with literature values. The best agreement is found with the data reported by Pelzel [22] and Sauerwald [29]. The viscosities of Zn plotted in Fig. 9 show very good agreement with data reported by most workers.

Clearly, the DC method yields accurate and reliable results for density, surface tension, and viscosity when compared with measurements using other techniques.

\subsection{Physicochemical Properties of Sb-Sn alloys}

In this section the results for properties of $\mathrm{Sb}-\mathrm{Sn}$ alloys containing $(10,20,25,50$, and 75) at $\%$ of Sb are discussed and presented in Figs. 10, 11, 12. The results are also compared with literature data. Figure 10 shows our results for the density (solid points only) compared with the results of other authors (solid lines with open points 
Table 3 Parameters of Arrhenius equation $A \mathrm{e}^{E /(R T)}$, with errors $(\mathrm{mPa} \cdot \mathrm{s})$. Viscosity for $\mathrm{Sb}, \mathrm{Sn}, \mathrm{Zn}$, and $\mathrm{Sb}-\mathrm{Sn}$ alloys

\begin{tabular}{|c|c|c|c|c|}
\hline \multirow[t]{2}{*}{ Materials } & \multicolumn{4}{|c|}{$\eta=A \mathrm{e}^{E /(R T)}(\mathrm{mPa} \cdot \mathrm{s})$} \\
\hline & $A$ & $\delta A$ & $E$ & $\delta E$ \\
\hline $\mathrm{Sn}$ & 0.315 & 0.029 & 8488.6 & 57.1 \\
\hline SnSb10 & 0.280 & 0.012 & 9334.1 & 61.4 \\
\hline $\mathrm{SnSb} 20$ & 0.272 & 0.017 & 9710.8 & 87.8 \\
\hline $\mathrm{SnSb} 25$ & 0.262 & 0.020 & 10301.0 & 119.5 \\
\hline SnSb50 & 0.259 & 0.017 & 11619.6 & 115.0 \\
\hline $\mathrm{SnSb} 75$ & 0.171 & 0.017 & 15480.7 & 263.4 \\
\hline $\mathrm{Sb}$ & 0.160 & 0.014 & 16938.1 & 151.8 \\
\hline $\mathrm{Zn}$ & 0.394 & 0.031 & 13497.3 & 124.6 \\
\hline
\end{tabular}

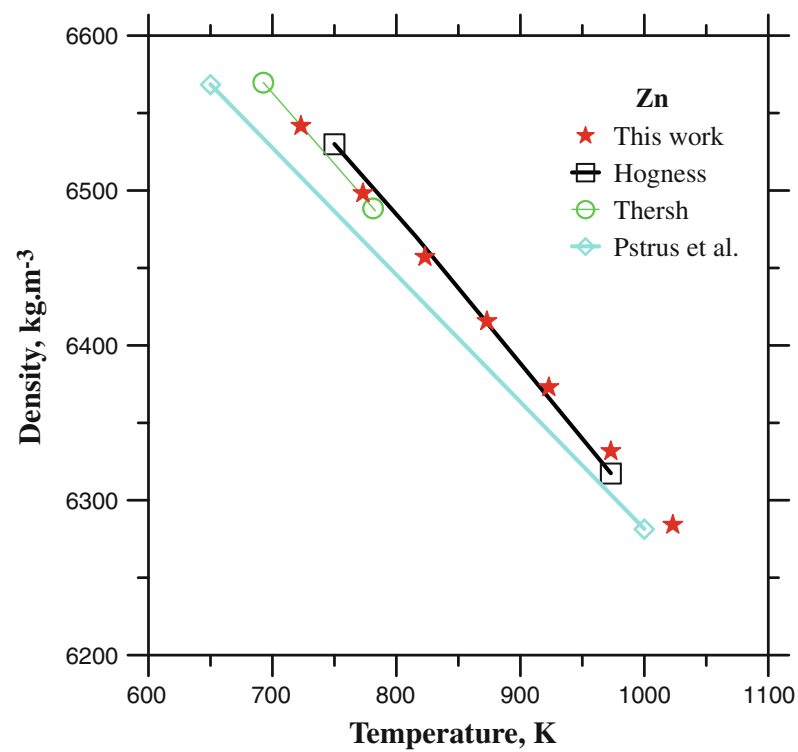

Fig. 7 Density of zinc as a function of temperature compared with literature data of Pstrus et al. [11], Hogness [12], and Thersh [17]

[20], solid lines with crosses [1], and dotted lines with points [47]). The measurement results show that the density of all investigated alloys decreases linearly with increasing temperature and they decrease with increasing Sb content.

An analysis of the data presented in Fig. 10 shows that the results of density measurements using the DC method for alloys SnSb10, SnSb20, SnSb25, SnSb50, and SnSb75 (composition in at\%) show very good agreement with data reported by Gasior et al. [20] obtained using the dilatometric method. The results obtained for other Sn$\mathrm{Sb}$ alloys are close to those reported by Sato and Munakata [47] and Plevachuk et al. [1]. It should be noted that the results for $\operatorname{SnSb10~(at\% )~are~nearly~the~same~as~those~}$ reported by Gasior et al. [20] who used a dilatometric technique-but are slightly lower than those reported by Plevachuk et al. [1] who used the sessile-drop method. 


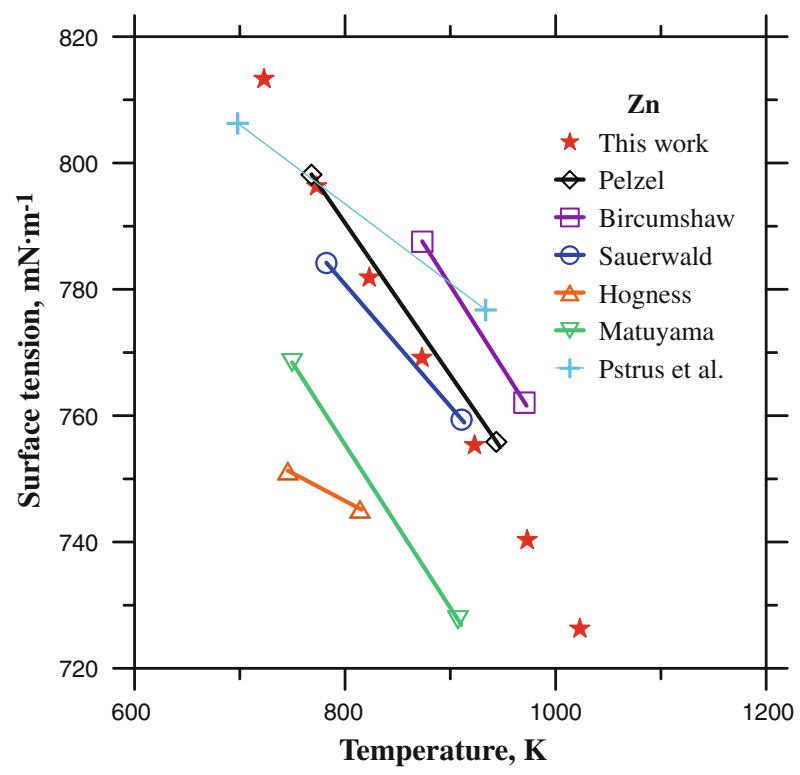

Fig. 8 Surface tension of zinc as a function of temperature compared with literature data of Pstrus et al. [11], Hogness [12], Pelzel [22], Bircumshaw [28], Sauerwald [29], and Matuyama [30]

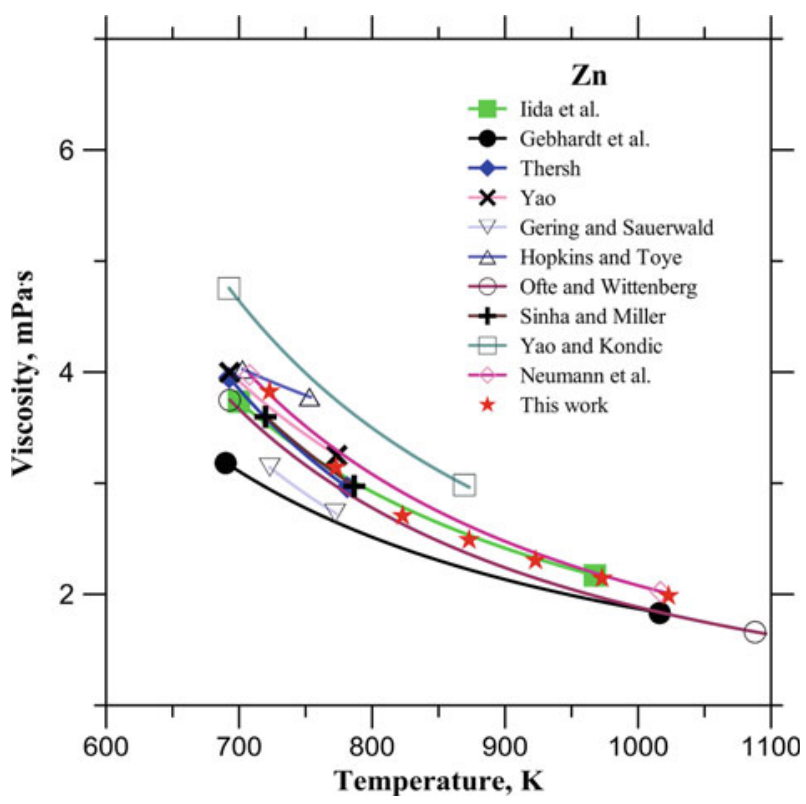

Fig. 9 Viscosity of zinc as a function of temperature compared with literature data of Iida et al. [31], Gebhardt et al. [32], Yao [39], Gering and Sauerwald [40], Hopkins and Toye [41], Ofte and Wittenberg [42], Sinha and Miller [43], Yao and Kondic [44], Neumann et al. [45], and Thersh [59] 


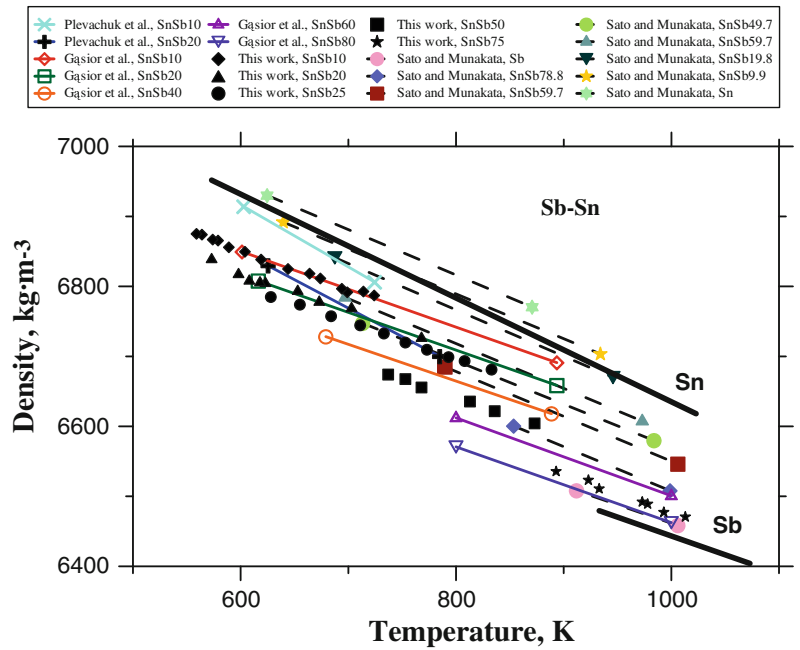

Fig. 10 Density of Sb-Sn alloys as a function of temperature compared with literature data of Plevachuk et al. [1], Sato and Munakata [47], and Gasior et al. [20]

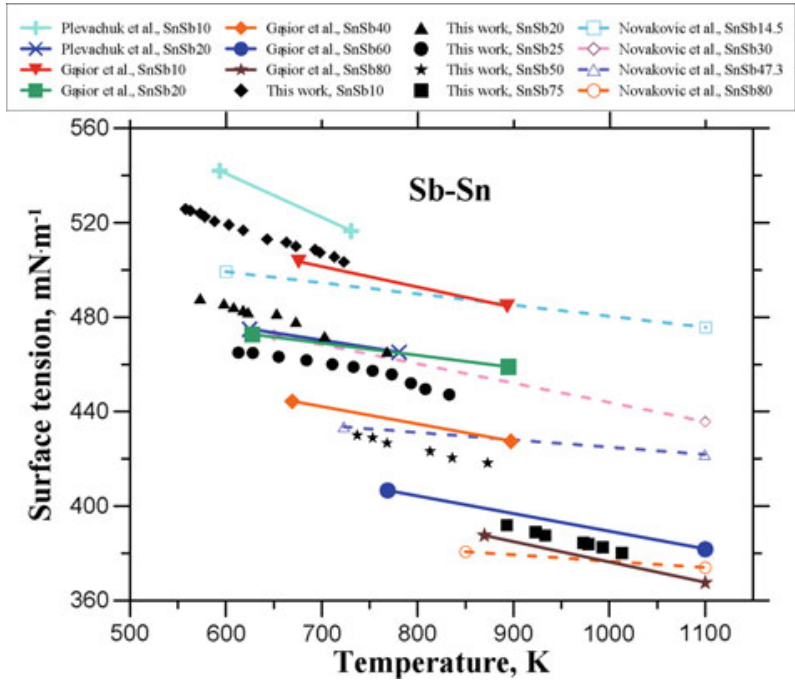

Fig. 11 Surface tension of Sb-Sn alloys as a function of temperature compared with literature data of Plevachuk et al. [1], Novakovic et al. [2], and Gasior et al. [20]

Also, the results of Plevachuk et al. [1] show a stronger temperature dependence than those of this study, of Gasior et al. [20], and of Sato and Munakata [47]. The results for density from this study (Fig. 10) are fitted to a straight line using the least-squares method. The resulting least-squares coefficients along with their corresponding errors are presented in Table 1 for each composition of the $\mathrm{Sb}-\mathrm{Sn}$ alloys.

Figure 11 shows the results of measurements for the surface tension of $\mathrm{Sn}-\mathrm{Sb}$ alloys. The surface tension of the alloys tested decreases linearly with increasing temperature 
Fig. 12 (a) Viscosity of Sb-Sn alloys as a function of temperature compared with literature data of Sato and Munakata [47]. (b) Viscosity of $\mathrm{Sn}$ and selected $\mathrm{Sb}-\mathrm{Sn}$ alloys as a function of temperature. Our experimental data from DC method compared with results of Sato and Munakata [47] and Plevachuk et al. [48], both from oscillation method
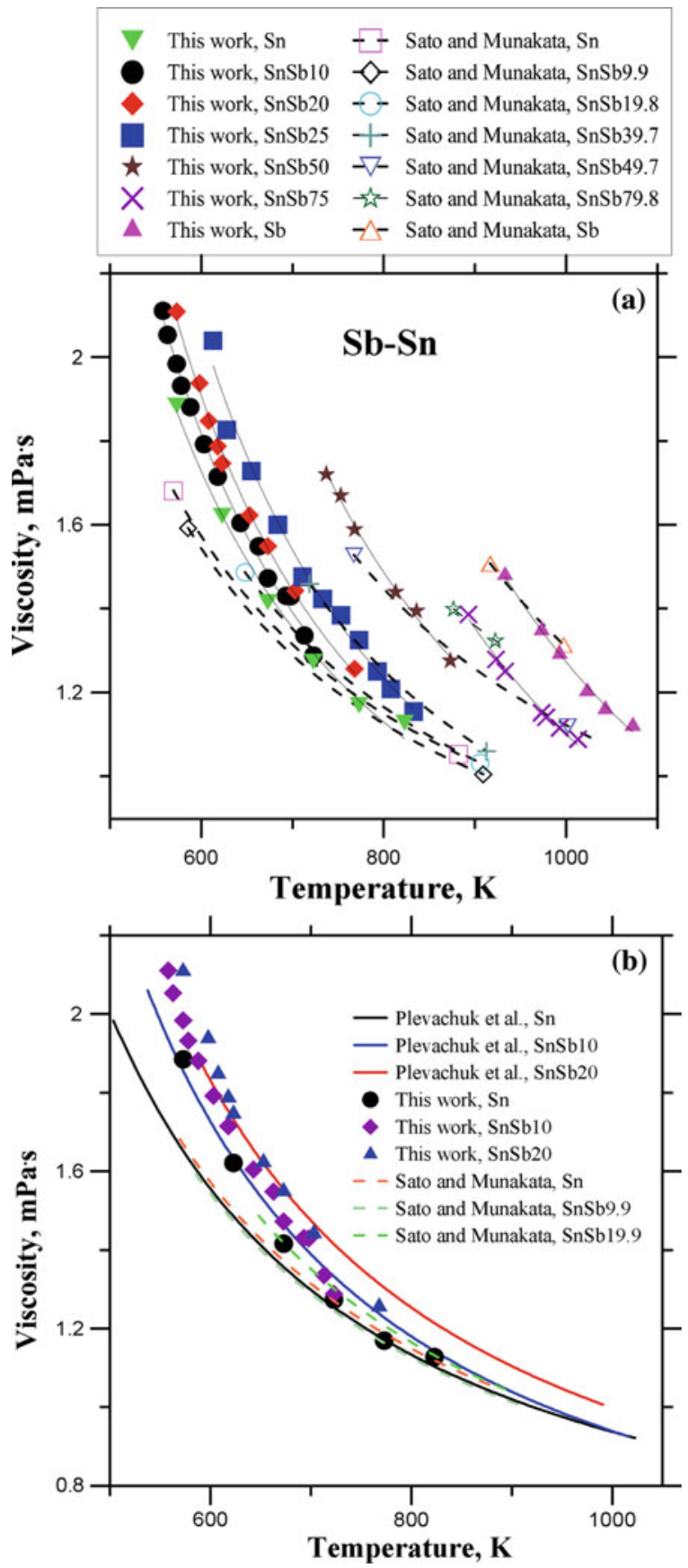

for each of the compositions, and it decreases with increasing antimony content in the alloy. The results are compared with the data of Gasior et al. [20] obtained with the maximum bubble-pressure method and the data of Plevachuk et al. [1] and Novakoivc 
et al. [2] using the sessile-drop method. There is very good agreement of our results with data $[1,20]$ for the SnSb20 alloy and data [20] for the SnSb10 alloy, while other data are slightly higher. In the case of the SnSb10 alloy, the results of Plevachuk et al. [1] are about 5\% higher than those reported in the study of Gasior et al. [20]. The data by Novakovic et al. [2] for the SnSb14.5 alloy fit the trend well, but the rest of the values of the surface tension for alloys richer in $\mathrm{Sb}$ are higher. Note that when measuring the surface tension by the sessile-drop method, the density is an input parameter whose value influences the result. In this way, the surface tension of the SnSb10 alloy is perhaps overestimated due to the higher value of density reported. The results from this study (Fig. 11) are fitted by a linear function, which is presented in Table 2 together with calculated errors for the coefficients $A$ and $B$.

The viscosities of $\mathrm{Sn}-\mathrm{Sb}$ alloys are shown in Fig. 12a, together with the data of Sato and Munakata [6,47]. The results are in good agreement with respect to the effect of temperature and $\mathrm{Sb}$ content. The viscosity values obtained are described by an Arrhenius equation, and the values of coefficients $A$ and $E$ are shown in Table 3. In Fig. 12b a comparison of viscosity data using the oscillation method by Sato and Munakata [6,47] and Plevachuk et al. [48] with our experimental data obtained from the DC method is presented. We can see that the data for pure tin is the same for the oscillation method, but with the addition of $\mathrm{Sb}$, the data from the same method changes somewhat. The oscillation method and the DC method yield the same values of activity in the same ranges of temperature. The values of viscosity from Plevachuk et al. [48] and the experimental data in this work for $\mathrm{SnSb} 10$ and $\mathrm{SnSb} 20$ are different by at most $5 \%$.

As illustrated in Figs. 10, 11, and 12a, b, the measurements for Sn-Sb alloys demonstrate the reliability of the DC method. The obtained results for the density, surface tension, and viscosity correlate well with literature data. These values provide a complete and consistent description of the physicochemical properties for the $\mathrm{Sb}-\mathrm{Sn}$ system.

\subsection{Modeling of Physical Properties in Sb-Sn System}

The following equation is used to calculate the density [20], and is compared with the results from this study given by the best fit line and with other literature values and presented in Fig. 13:

$$
\begin{aligned}
\rho_{\mathrm{Sb}-\mathrm{Sn}} & =\rho_{\mathrm{Sb}} X_{\mathrm{Sb}}+\rho_{\mathrm{Sn}} X_{\mathrm{Sn}}+\Delta \rho \\
\Delta \rho & =91.60 X_{\mathrm{Sb}}^{2}-88.68 X_{\mathrm{Sb}}-3.51
\end{aligned}
$$

where $\rho_{\mathrm{Sb}}-\mathrm{Sn}$ is the density of Sb-Sn alloys, $\rho_{\mathrm{Sb}}$ and $\rho_{\mathrm{Sn}}$ are the densities of Sb and $\mathrm{Sn}$, and $X_{\mathrm{Sb}}$ and $X_{\mathrm{Sn}}$ are the mole fractions of Sb and Sn, respectively. In Fig. 13, an isotherm for the density at $923 \mathrm{~K}$ is presented. Excellent agreement is observed between the results from this study and those calculated using Eq. 1 .

The molar volumes $V_{\mathrm{m}}\left(\mathrm{m}^{3} \cdot \mathrm{mol}^{-1}\right)$ of the $\mathrm{Sb}-\mathrm{Sn}$ system at $923 \mathrm{~K}$ are presented in Fig. 14. The calculations of $V_{\mathrm{m}}$ were carried out using Eq. 3 . 


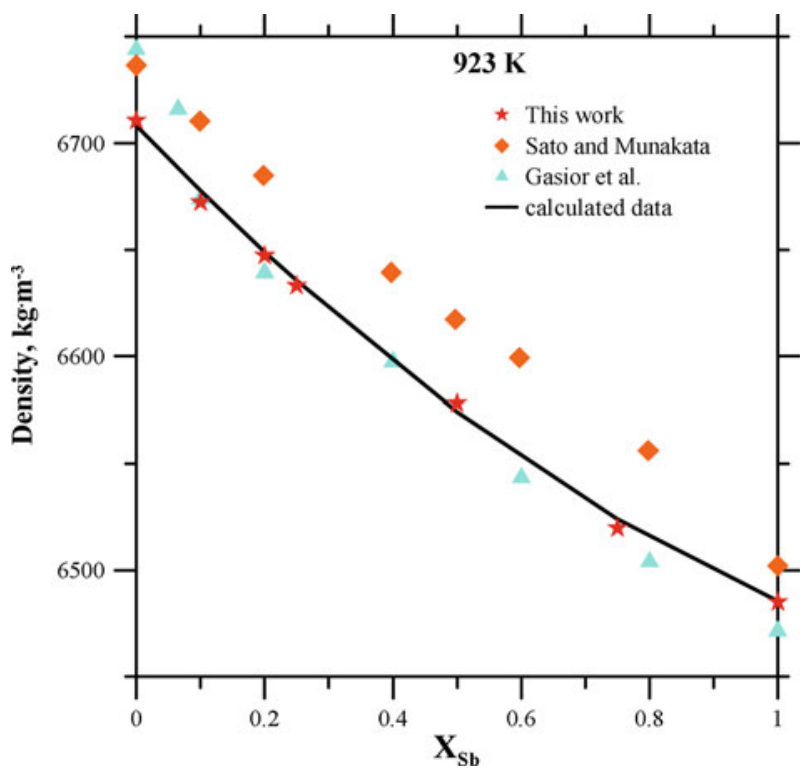

Fig. 13 Density isotherms of liquid Sb-Sn alloys calculated from Eq. 1 (continues lines) together (symbols) with experimental data calculated using equations listed in Table 1 and literature data of Sato and Munakata [47] and Gasior et al. [20]

$$
V_{\mathrm{m}}=\frac{M_{\mathrm{Sb}} X_{\mathrm{Sb}}+M_{\mathrm{Sn}} X_{\mathrm{Sn}}}{\rho}
$$

where $M_{\mathrm{Sb}}$ and $M_{\mathrm{Sn}}$ are the respective atomic weights.

The Butler model [60] was used to model the surface tension as described in an earlier work by Gancarz et al. [49] and by Gasior et al. [20]. The optimized thermodynamic parameters were taken from Jonsson and Agren [61]. The Butler model then yields the temperature dependencies of the surface tension for experimental compositions that are plotted in Fig. 15 in comparison with experimental data and other literature values.

For the modeling of viscosity, the following models were used: Moelwyn-Hughes [62], Sichen et al. [63], Seetharaman and Sichen [64], Kozlov-Romanov-Petrov [65], Kaptay [66], and Morita-Iida-Ueda [67]. A detailed description of these models has been reported in earlier work [4]. A comparison of experimental data with each of these models is presented in Fig. 16. As can be seen, the model of Sichen et al. [63] gives the best fit to the experimental data.

\section{Summary}

The DC method was used to generate values of the density, surface tension, and viscosity for $\mathrm{Sn}-\mathrm{Sb}$ alloys. At first the experimental setup was calibrated using pure $\mathrm{Sn}$, $\mathrm{Sb}$, and $\mathrm{Zn}$. The determined relationships of the above properties versus temperature for these pure metals agreed very well with those reported in the literature. The DC 


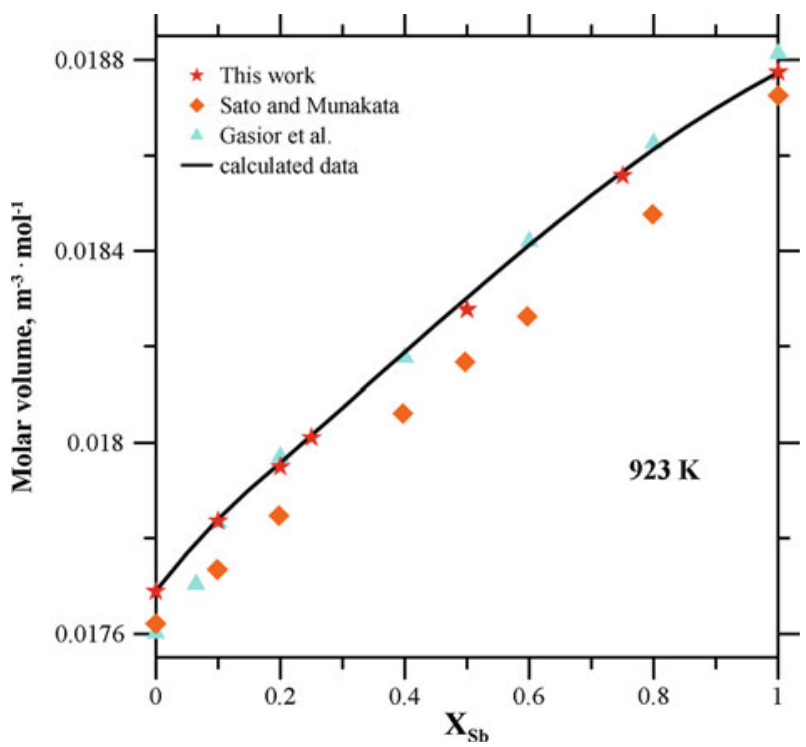

Fig. 14 Molar volume of the Sb-Sn liquid alloys calculated using Eqs. 1 and 2 (continuous lines). Symbols are experimental values calculated from Eq. 3 and literature data (Sato and Munakata [6] and Gasior et al. [20])

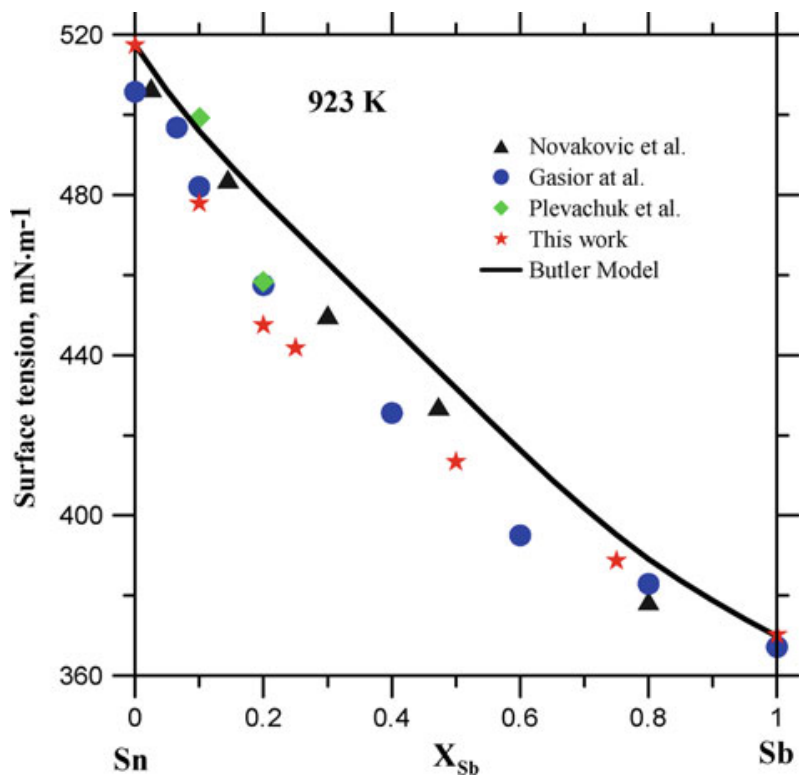

Fig. 15 Surface tension isotherms of the liquid $\mathrm{Sb}-\mathrm{Sn}$ liquid alloys obtained from Butler's model (continuous lines) against the background of experimental values calculated from equations in Table 2, with literature data (symbols) $[1,2,20]$. Dashed lines show the linear changes of surface tension between pure $\mathrm{Sb}$ and $\mathrm{Sn}$ 


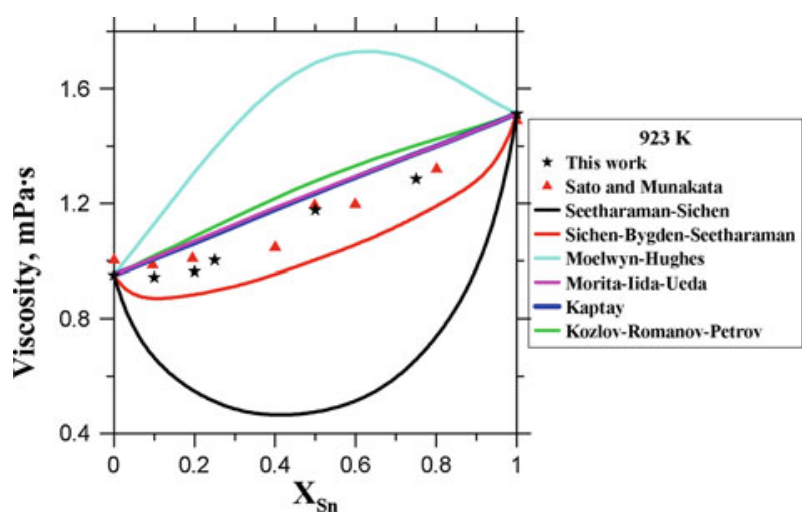

Fig. 16 Comparison of viscosity Sb-Sn alloys with models: Moelwyn-Hughes [62], Sichen et al. [63], Seetharaman and Sichen [64], Kozlov et al. [65], Kaptay [66], Morita et al. [67] and this work and literature data of Sato and Munakata [47] for $923 \mathrm{~K}$

and oscillatory methods are both indirect methods. The viscosity values obtained for pure antimony and tin can affect the results of $\mathrm{Sb}-\mathrm{Sn}$ alloys. The difference in results for pure metals may be due to calibration. Both of these methods require calibration. Therefore, the differences in density and viscosity values for the pure metals Sb and Sn can result in the DC method yielding higher values of viscosity than those of Sato and Munakata [47]. The density results obtained by the dilatometric method agree very well with literature values $[1,20]$. The values of the surface tension in the work [1,2] investigated by the sessile-drop and maximum bubble-pressure methods [20] agree very well with the trend of experimental data obtained using the DC method. For both the sessile-drop and DC methods, density plays an important role, as it is involved directly in the calculation of the surface tension. This could cause differences in the results of the experiment [1,2]. The comparisons of experimental and literature data show very good agreement and confirm the resultant values obtained using the DC method. Clearly, the DC method gave a consistent and complete description of the viscosity, density, and surface tension for the $\mathrm{Sb}-\mathrm{Sn}$ system over a wide range of temperatures and compositions.

Open Access This article is distributed under the terms of the Creative Commons Attribution License which permits any use, distribution, and reproduction in any medium, provided the original author(s) and the source are credited.

\section{References}

1. Yu. Plevachuk, W. Hoyer, I. Kaban, M. Kohler, R. Novakovic, J. Mater. Sci. 45, 2051 (2010)

2. R. Novakovic, D. Giuranno, E. Ricci, S. Delsante, D. Li, G. Borzone, Surf. Sci. 605, 248 (2011)

3. A.A. El-Daly, Y. Swilern, A.E. Hammad, J. Alloys Compd. 471, 98 (2009)

4. S.W. Chen, C.C. Chen, W. Gierlotka, A.R. Zi, P.Y. Chen, H.J. Wu, J. Electron. Mater. 37, 992 (2008)

5. S. Chen, P. Chen, C. Wang, J. Electron. Mater. 35, 1982 (2006)

6. T. Sato, S. Munakata, Bull. Res. Inst. Miner. Dressing Metall., Tohoku Univ. 10, 173 (1954)

7. H.J. Fisher, A. Phillips, JOM-J.: Min. Met. Mat. 6, 1060 (1954) 
8. H.T. Greenway, J. Inst. Met. 74, 133 (1948)

9. W.R. Gale, T.C. Totemaier (eds.), Smithells Metals Reference Book (Elsevier, Butterworth-Heinemann Ltd., Oxford, 2004)

10. J. Pstrus, Physico-chemical Properties of New Solder Alloys on Example of Sn-Zn-In System (Ph.D. Thesis, Krakow, 2008)

11. J. Pstrus, Z. Moser, W. Gasior, A. Debski, Arch. Metall. Mater. 51, 335 (2006)

12. T.R. Hogness, J. Am. Chem. Soc. 43, 1621 (1921)

13. D. Steinberg, Metall. Trans. 5, 1341 (1974)

14. M. Kucharski, P. Fima, Monatsh. Chem. 136, 1841 (2005)

15. M. Kucharski, Arch. Hut. 22, 181 (1977)

16. P.E. Berthou, R. Tougas, Metall. Trans. 1, 2978 (1970)

17. H.R. Thresh, J. Amer. Chem. Soc. 43, 1621 (1968)

18. B.J. Keene, Int. Mater. Rev. 38, 157 (1993)

19. K.C. Mills, Y.C. Su, Int. Mater. Rev. 51, 329 (2006)

20. W. Gasior, Z. Moser, J. Pstrus, J. Phase Equilib. 24, 504 (2003)

21. D.R. Lide (ed.), CRC Handbook of Chemistry and Physics, 88th edn. (CRC Press, Boca Raton, FL, 2007-2008)

22. E. Pelzel, Z. Metallkd. 93, 248 (1952)

23. V. Somol, M. Beranek, Sb. Vysk. Sk. Chem. -Technol. B30, 199 (1984)

24. I. Lauerman, F. Sauerwald, Z. Metallkd. 55, 605 (1964)

25. V.B. Lazarev, Russ. J. Phys. Chem. 38, 325 (1964)

26. J. Lee, W. Shimoda, T. Tanaka, Mater. Trans. 45, 2864 (2004)

27. T. Tanaka, K. Hack, T. Iida, S. Hara, Z. Metallkd. 87, 380 (1996)

28. L.L. Bircumshaw, Phil. Mag. 1286 (1937) in E. Pelzel [22]

29. F. Sauerwald, Z. Anorg. Chem. 154, 79 (1926) in E. Pelzel [22]

30. Y. Matuyama, Sci. Tohoku Univ. 16, 555 (1927) in E. Pelzel [22]

31. T. Iida, Z. Morita, S. Takeuchi, J. Jpn. Inst. Metals. 39, 1169 (1975)

32. E. Gebhardt, M. Becker, E. Tragner, Z. Metallkd. 44, 379 (1953)

33. E. Gebhardt, M. Becker, S. Dorner, Z. Metallkd. 45, 83 (1954)

34. E. Gebhardt, K. Kostlin, Z. Metallkd. 48, 636 (1957)

35. F. Sauerwald, Z. Metallkd. 26, 259 (1934)

36. V.G. Postolov, E.P. Romanov, V.P. Kondrat'ev, V.I. Kononenko, High Temp. 41, 762 (2003)

37. F. Herwing, M. Wobst, Z. Metallkd. 83, 35 (1992)

38. H. Nakajima, Trans. Jpn. Inst. Met. 17, 403 (1976)

39. T. Yao, Z. Metallkd, Giesserei. Tech-Wiss. Beich. 16, 837 (1956)

40. K. Gering, F. Sauerwald, Z. Anorg, Chem. 223, 204 (1935)

41. M.R. Hopkins, T.C. Toye, Proc. Phys. Soc. B63, 773 (1950)

42. D. Ofte, L.J. Wittenberg, Trans. Metall. Soc. AIME 227, 706 (1963)

43. A. Sinha, E. Miller, Metall. Trans. 1, 1356 (1970)

44. T.P. Yao, V. Kondic, J. Inst. Met. 81, 17 (1952-1953)

45. H. Neumann, Ch. Dong, Yu. Plevachuk, Z. Metallkd. 91, 933 (2000)

46. W. Gasior, Z. Moser, J. Pstrus, M. Kucharski, Arch. Metall. 46, 23 (2001)

47. T. Sato, S. Munakata, Bull. Res. Inst. Miner. Dressing Metall. Tohoku Univ. 11, 183 (1955)

48. Yu. Plevachuk, V. Sklyarchuk, A. Yakymovych, P. Svec, D. Janickovic, E. Illekova, J. Mater. Sci. - Mater. Electron. 22, 631 (2011)

49. T. Gancarz, Z. Moser, W. Gasior, J. Pstrus, H. Henein, Int. J. Thermophys. 32, 1210 (2011)

50. S.J. Roach, H. Henein, Can. Metall. Q. 42, 175 (2003)

51. S.J. Roach, H. Henein, Metall. Mater. Trans. B 36, 667 (2005)

52. H. Henein, Can. Metall. Q. 44, 261 (2004)

53. P. Fima, T. Gancarz, J. Pstrus, K. Bukat, J. Sitek, Solder. Surf. Mount Technol. 24, 71 (2012)

54. M.G. Johnson, hooke.c: nonlinear optimization using the algorithm of Hooke and Jeeves, http://www. netlib.org/opt/hooke.c 1994, based on A.F. Kaupe Jr, Algorithm 178, Direct Search, contain amendments Bell and Pike, CACM v. 9, 684, Sept (1966) and the Tomlin and Smith, Remark on Algorithm 178, CACM v.12

55. L. Lucas, Tech. Met. Res. IV 2, 219 (1970)

56. W. Klemm, H. Spitzer, H. Nierman, Angew. Chem. 2, 985 (1960)

57. A. Kirshenbaum, J. Cahill, Trans. ASM 55, 849 (1962) 
58. A. Crawley, D. Kiff, Metall. Trans. 3, 157 (1972)

59. H.R. Thresh, Trans. Metall. Soc. AIME 233, 79 (1965)

60. J.A.V. Butler, Proc. R. Soc. Lond. Ser. A CXXXV, 348 (1932)

61. B. Jönsson, J. Ågren, Mater. Sci. Technol. 2, 913 (1986)

62. E.A. Moelwyn-Hughes, Phys. Chem. 434, (1970)

63. D. Sichen, J. Bygdén, S. Seetharaman, Metall. Mater. Trans. B 25, 519 (1994)

64. S. Seetharaman, D. Sichen, Metall. Mater. Trans. B 25, 589 (1994)

65. L.M. Kozlov, L.M. Romanov, N.N. Petrov, Izv. Vuzov. Chernaya Metall. 3, 7 (1983)

66. G. Kaptay, Proceedings of MicroCAD 2003, International Conference Section: Metallurgy, vol. 23 (University of Miskolc, Hungary, 2003)

67. Z. Morita, T. Iida, M. Ueda, in Liquid Metals, Institute of Physics Conference, vol. 30, Bristol, 1977 , p. 600 